\title{
() OPEN ACCESS \\ Identifying leadership in medical trainees: evaluation of a competency-based approach
}

\author{
Samantha K. Jones (1) , ${ }^{1}$ Ka Hong Chan, ${ }^{2}$ Joshua S. Bourdage, ${ }^{1}$ Aleem Bharwani (i) ${ }^{3}$
}

- Additional supplemental material is published online only. To view, please visit the journal online (http://dx.doi. org/10.1136/leader-2020000402)

${ }^{1}$ Psychology, University of Calgary, Calgary, Alberta, Canada

${ }^{2}$ Division of Internal Medicine, The University of British Columbia Faculty of Medicine, Vancouver, British Columbia, Canada

${ }^{3}$ Department of Medicine, Cumming School of Medicine, University of Calgary, Calgary, Alberta, Canada

\section{Correspondence to}

Samantha K. Jones, Psychology, University of Calgary, Calgary, Alberta, Canada;

samantha.jones1@ucalgary.ca

Some of the data presented in this report were presented at the 2019 European Association for Work and Organization Psychology (EAWOP) Small Group Meeting on Leadership and Health/Well-being in Exeter, United Kingdom and were accepted for presentation at the 2020 International Conference on Residency Education (ICRE) in Vancouver, British Columbia.

Received 18 October 2020 Revised 14 April 2021 Accepted 4 May 2021
Check for updates

(c) Author(s) (or their employer(s)) 2021. Re-use permitted under CC BY-NC. No commercial re-use. See rights and permissions. Published by BMJ.

To cite: Jones SK, Chan $\mathrm{KH}$, Bourdage JS, et al. BMJ Leader Published Online First: [please include Day Month Year]. doi:10.1136/ leader-2020-000402

\section{ABSTRACT}

Background As medical professional roles diversify, it is essential to understand what makes effective medical leaders. This study develops and validates a medical leadership competency framework that can be used to develop and evaluate leaders across all levels of medical organisations.

Method In Phase One, the authors derived desired leadership traits and behaviours in the medical context from a panel of subject matter experts (SMEs). Traits and behaviours were then combined into multifaceted competencies which were ranked and further refined through evaluation with additional SMEs. In Phase Two, the final seven competencies were evaluated with 181 medical trainees and 167 supervisors between 2017 and 2018 to determine the validity of rapid-form and longform leadership assessments of medical trainees. Self and supervisor reports of the seven competencies were compared with validated trait and leadership behaviour measures as well as clinical performance evaluations.

Results The final seven leadership competencies were: Ethical and Social Responsibility, Civility, Self-Leadership, Team Management, Vision and Strategy, Creativity and Innovation, and Communication and Interpersonal Influence. Results demonstrate initial validity for rapidform and long-form leadership evaluations; however, perceptions of good leadership may differ between trainees and supervisors. Further, negative leadership behaviours (eg, incivility) are generally not punished by supervisors and some positive leadership behaviours (eg, ethical leadership) were associated with poor leadership and clinical performance evaluations by supervisors. Supervisor perceptions of leadership were significantly driven by trainee scores on social boldness (a facet of extraversion).

Conclusions A multicompetency framework effectively evaluates leadership in medicine. To more effectively reinforcepositive leadership behaviours and discourage negative leadership behaviours in medical students and resident physicians, we recommend that medical educators:: (1) Use validated frameworks to build leadership curriculum and evaluations. (2) Use short-term and long-term assessment tools. (3) Teach assessors how to evaluate leaders and encourage positive leadership behaviours early in training.

Leadership in the medical context is associated with improvements in healthcare delivery, ${ }^{1}$ work attitudes of practitioners, ${ }^{23}$ and is valued as a critical component of medical education. ${ }^{4-6}$ Despite these important links, the definition, implementation and evaluation of medical leadership across trainees remain inconsistent, ${ }^{78}$ as current medical training continues to largely focus on technical, scientific-based skills. While leadership competency frameworks have emerged within medicine $e^{9-11}$ with the subsequent development of training programmes, ${ }^{48}$ authors continue to advocate for stronger evidence-based frameworks of leadership in the training and evaluation of medical trainees. Department or programme specific leadership measures might appear to tap into the idiosyncratic needs of each specialisation; however, these measures are often not developed in relation to existing validated theories of leadership, and we do not know if they (1) appropriately evaluate the relevant components of leadership and (2) are actually indicators of effective physicians. For example, although leadership is a domain in many competency frameworks in medical education (eg, CanMEDS $^{12}$ National Health Service $(\mathrm{NHS})^{13}$ with some exceptions, ${ }^{2}$ few frameworks and their evaluation tools have been validated to understand if they actually predict better medical leaders based on theories of leadership. This limits our capacity to define appropriate learning outcomes and monitor progress for medical trainees, and our ability to develop training opportunities that cultivate leadership. In essence, our understanding of the domain of leadership within medicine, and many of the tools currently used, could be better grounded in the established field of leadership theory.

Although numerous traditional leadership theories have migrated into the medical training and management field (eg, transformational leadership $\left.^{14}\right)$, many only target elements of good medical leadership without acknowledging the diversity of traits and behaviours that may be required of a healthcare provider (eg, leadership in clinical and administrative domains). Drawing on previous leadership work, ${ }^{15-17}$ we define medical leadership as the harnessing of medical knowledge, and interpersonal skills and abilities, by healthcare professionals to motivate and persuade others towards a common goal in both formal (eg, management positions) and informal (eg, acting as a leader during daily clinical work) settings. This definition captures the importance of excellence in the medical field, ${ }^{15}$ the motivation and persuasion of others, and the relevance of formal and informal leadership settings (ie, context). ${ }^{16} 17$ Further, we distinguish between leadership and leader, such that leadership encompasses the interpersonal processes involved in the behaviours highlighted above, while a leader is someone that successfully engages in these behaviours, bolstered by traits and other intrapersonal elements (eg, skills and experience) that enable them to successfully engage in leadership behaviours. ${ }^{18}$ In order to best identify areas of strengths and weaknesses in medical training, our 
goal is to develop and evaluate a comprehensive set of qualities that best define medical leadership and make recommendations for leadership training and evaluation moving forward. We move beyond previous frameworks that focused primarily on leadership behaviours to also include the underlying traits that contribute to the emergence and enactment of good leadership and proficiency within a competency domain. By tapping into the wealth of theories available in the fields of psychology and management, we aim to bring a multi-disciplinary lens to medical leadership that promotes validated measurement tools overlooked in previous studies. In doing so, we provide a competency-based framework that can be used for understanding leadership in a medical context and serve as a foundation for advancing the quality of medical education. Therefore, the purpose of our study is to address the following research questions:

1. What are the major competencies that define leadership in the medical context?

2. How are these leadership competencies exhibited by medical trainees and viewed by their supervisors?

3. What traits and behaviours underlie these competencies?

4. How do these competencies relate to clinical performance?

\section{METHOD}

Phase One: Defining leadership

The goal of the first phase was to establish the major competency domains involved in leadership in the medical context. As a starting point, we examined semistructured interviews with 77 subject matter experts (SMEs). These interviews were previously used to identify enablers and barriers to academic health leadership ${ }^{19-21}$ but also provided insights into how programme stakeholders viewed good leadership. We examined the results of these previously published interviews, and used these identified traits and behaviours as a guide to determine the more established models of leadership (eg, ethical leadership ${ }^{22}$ ) and associated competencies that may be relevant to medical leadership. This effort resulted in a preliminary pool of 14 leadership competency domains and definitions. Labels and definitions were drawn from the literature and adapted based on feedback from the members of our authorship team who work in a medical context.

To determine a final competency framework, in 2015 we had an additional 33 SMEs indicate the importance of each competency domain. To ensure that leadership was considered from a variety of perspectives, the 33 SMEs encompassed individuals in a variety of positions, including senior faculty $(n=6)$, junior faculty $(n=8)$, medical residents $(n=6)$, graduate students $(n=7)$ and staff from the undergraduate medical education $(n=5)$, and post-graduate medical education $(n=1)$ offices. Participants read each competency domain and definition and completed two measures. The first was an importance rating of each competency domain from 1 (low) to 7 (high). However, out of concern that SMEs might rate all of the competency domains important, and a desire to identify the most important leadership competency domains, we also had the SMEs rank what they believed were the three most important competency domains. Results can be found in table 1 .

The results of this survey indicated that in general, all 14 competency domains were seen as important (eg, the lowest mean was for Safety Orientation, at 5.30 out of 7). As such, we utilised both importance ratings and competency domain inclusion in the top three rank orderings to make our decisions about which competency domains to retain. Communication received
Table 1 Phase One leadership competency domains and ratings/ rankings of importance

\begin{tabular}{|c|c|c|c|c|c|}
\hline \multirow{2}{*}{$\begin{array}{l}\text { Leadership competency } \\
\text { domains }\end{array}$} & \multirow[b]{2}{*}{ Mean $(S D)^{*}$} & \multicolumn{4}{|c|}{ Rank ordering } \\
\hline & & First & Second & Third & Total \\
\hline Communication & $6.64(0.55)$ & 2 & 6 & 8 & 16 \\
\hline Civility & $6.12(0.86)$ & 2 & 1 & 3 & 6 \\
\hline Self-Leadership & $6.09(0.72)$ & 3 & 3 & 6 & 12 \\
\hline Interpersonal Influence & $6.09(0.77)$ & 2 & 3 & 3 & 8 \\
\hline $\begin{array}{l}\text { Ethical Leadership and } \\
\text { Social rRsponsibility }\end{array}$ & $6.09(0.68)$ & 2 & 1 & 1 & 4 \\
\hline Team Management & $6.06(0.83)$ & 3 & 4 & 3 & 10 \\
\hline Creativity and Innovation & $5.97(0.95)$ & 3 & 2 & 3 & 8 \\
\hline Strategy & $5.94(0.83)$ & 2 & 7 & 3 & 12 \\
\hline Vision & $5.91(0.93)$ & 11 & 1 & 3 & 15 \\
\hline $\begin{array}{l}\text { Forming Teams and Task } \\
\text { Management }\end{array}$ & $5.91(0.84)$ & 3 & 3 & 6 & 12 \\
\hline Project Management & $5.91(0.88)$ & 1 & 1 & 2 & 4 \\
\hline $\begin{array}{l}\text { Decision and Judgement } \\
\text { Analytics }\end{array}$ & $5.85(0.91)$ & 2 & 2 & 4 & 8 \\
\hline $\begin{array}{l}\text { Diversity and Intercultural } \\
\text { Awareness }\end{array}$ & $5.58(0.83)$ & 0 & 2 & 0 & 2 \\
\hline Safety & $5.30(1.13)$ & 0 & 0 & 0 & 0 \\
\hline
\end{tabular}

Due to small sample sizes, means and rankings were not compared between different subgroups of subject matter experts.

*Measured on a 1 (low importance) to 7 (high importance) Likert scale.

both the highest mean for importance, and was included in the number of top three rankings most often. Others, such as Vision, had a lower relative importance rating (ie, 11th out of 14) but received a high number of top three rankings-in this case, the greatest number of first place rankings-and so was retained. Competency domains such as Project Management, Decision and Judgement Analytics, and Forming Teams and Task Management were rated as both less important and had few individuals rate them as in the top three. Considering both types of data, five competency domains were eliminated from further consideration, and others were either retained as is (eg, Ethical and Social Responsibility, Civility, Self-Leadership). In addition, we examined remaining competency domains to see if any could be thematically combined, which led to Communication and Interpersonal Influence being combined into one competency domain, as well as combining Vision and Strategy. Similarly, we incorporated some elements of the Task Management competency domain into the Team Management competency domain, given the importance of such behaviours in the leadership literature. ${ }^{23}$ The results of Phase One led to a focused competency framework consisting of seven leadership competency domains: Ethical and Social Responsibility, Civility, Self-Leadership, Team Management, Vision and Strategy, Creativity and Innovation, and Communication and Interpersonal Influence (for definitions/competencies, see table 2).

\section{Phase Two: Evaluating leadership}

To address research questions $2-4$, we developed a self-report survey of leadership to be completed by medical trainees, as well as a shortened version to be completed by supervisors ${ }^{\mathrm{a}}$ to provide a multisource evaluation of leadership competencies. Self-report leadership measures were completed by $181^{\mathrm{b}}$ medical trainees (students: $\mathrm{n}=64,35.3 \%$; residents: $\mathrm{n}=117,64.6 \%$ ) at a mid-sized western Canadian university between November 2017 and September 2018. Trainees were invited to participate by a research team member that was not in an evaluative 
Table 2 Definitions and measurement items of leadership competency domains

\begin{tabular}{|c|c|c|}
\hline Competency domain & Competencies & Measurement scales \\
\hline $\begin{array}{l}\text { Ethical and Social } \\
\text { Responsibility }\end{array}$ & $\begin{array}{l}\text { I demonstrate honesty, integrity, fairness, and trustworthiness. I clearly establish } \\
\text { high ethical standards, and uphold these standards through the use of rewards and } \\
\text { punishments. I actively communicate the importance of ethics to others, particularly } \\
\text { with respect to the ethical implications of my day-to-day training and work. Lastly, } \\
\text { I demonstrate a strong commitment to social responsibility in terms of community, } \\
\text { society, and environment. }\end{array}$ & $\begin{array}{l}\text { Ethical leadership }{ }^{22} \text { - adapted ( } 5 \text { items) } \\
\text { Honesty-humility }{ }^{33} \text {-fairness ( } 4 \text { items) and sincerity ( } 4 \\
\text { items) }\end{array}$ \\
\hline Civility & $\begin{array}{l}\text { I consistently treat others with dignity and respect, and act with regard to other's } \\
\text { feelings. Even under stressful conditions, I refrain from incivil verbal and nonverbal } \\
\text { behaviours such as shouting or swearing, intimidation, bullying, rudeness, ridiculing, } \\
\text { silent treatment, making threatening comments, and causing emotional distress to } \\
\text { others (including peers, subordinates, and interdisciplinary team members). }\end{array}$ & $\begin{array}{l}\text { Incivility }{ }^{34} \text {-adapted ( } 5 \text { items) } \\
\text { Agreeableness }{ }^{33} \text {-forgiveness ( } 4 \text { items) and patience ( } 4 \\
\text { items) }\end{array}$ \\
\hline Self-Leadership & $\begin{array}{l}\text { I am effective in several personal areas, including being organised, efficient, and exhibit } \\
\text { effective time management. I am also reflective and strive for self-improvement, and } \\
\text { demonstrate the ability to learn and grow. }\end{array}$ & $\begin{array}{l}\text { Learning goal orientation }{ }^{35} \text {-adapted ( } 5 \text { items) } \\
\text { Conscientiousness }{ }^{33} \text {-organisation ( } 4 \text { items) and diligence } \\
\text { (4 items) }\end{array}$ \\
\hline Team Management & $\begin{array}{l}\text { I define leader and group member roles, initiate actions, organise group activities, and } \\
\text { define how tasks are to be accomplished by the group. This includes effectiveness in } \\
\text { areas such as selecting and assembling a team, talent recognition, recognising and } \\
\text { rewarding the team, adapting to new challenges, and succession planning. I am also } \\
\text { concerned with the well-being of my followers and I am personable and understanding. } \\
\text { This includes creating a supporting environment, diagnosing group dynamics, conflict } \\
\text { resolution, personality awareness, and empowering my team. }\end{array}$ & $\begin{array}{l}\text { Initiating structure (5 items) and consideration (5 items) } \\
\text { Behaviours }^{36}\end{array}$ \\
\hline Vision and Strategy & $\begin{array}{l}\text { I set and create an ambitious long-term vision and forecast and create opportunities } \\
\text { for growth at the faculty of medicine. I understand how my role contributes to other's } \\
\text { visions and I formulate and implement the strategy for achieving the Faculty of } \\
\text { Medicine's vision. I understand the core business of the Faculty of Medicine, I take a } \\
\text { systems perspective that focuses on long-term organisational priorities, I recognise the } \\
\text { need for and initiate change, and engage with others to support the strategy. }\end{array}$ & $\begin{array}{l}\text { Strategic leadership }{ }^{37} \text { ( } 8 \text { items) } \\
\text { Transformational leadership—adapted ( } 6 \text { items })^{38}\end{array}$ \\
\hline Creativity and Innovation & $\begin{array}{l}\text { I develop new insights into situations and apply innovative solutions to make team/ } \\
\text { organisational improvements. I also create a climate that encourages creative thinking } \\
\text { and innovation and design and implement new or progressive ways of doing things. }\end{array}$ & $\begin{array}{l}\text { Openness }{ }^{33} \text { - creativity ( } 4 \text { items) and unconventionality (4 } \\
\text { items) } \\
\text { Propensity to innovate }{ }^{39} \text { ( } 5 \text { items) }\end{array}$ \\
\hline $\begin{array}{l}\text { Communication and } \\
\text { Interpersonal Influence }\end{array}$ & $\begin{array}{l}\text { I actively listen, and both seek and am open-minded to others' opinions, ideas, and } \\
\text { perspectives. I am also able to communicate my ideas in a persuasive, accurate, and } \\
\text { clear manner, projecting credibility. I tailor my communication to the audience. I have } \\
\text { the ability to engage in diplomacy/negotiations, build consensus, and effectively engage } \\
\text { the frontline. I am politically savvy in effectively navigating the political landscape of the } \\
\text { Faculty of Medicine. }\end{array}$ & $\begin{array}{l}\text { Political skill }{ }^{40} \text { ( } 6 \text { items) } \\
\text { Extraversion }^{33} \text { - social boldness ( } 4 \text { items) and sociability } \\
(4 \text { items }) \\
\text { Clinical communication—adapted SEGUE }{ }^{41} \text { ( } 6 \text { items) }\end{array}$ \\
\hline
\end{tabular}

Items in the adapted measures have been chosen to maximise applicability to trainees in the medical context, ensure a unified response scale (eg, SEGUE is traditionally presented as a true/false measure), and to ensure the appropriate referent for the present study (eg, peers vs subordinate).

position relative to any of the trainees and received a gift card for their participation (valued at \$C25). They consented to leadership evaluation by their supervisors and the release of clinical performance data that was subsequently anonymised. As a result, members of the research team directly affiliated with the Faculty of Medicine never had access to identifying data. Participants were assured their responses would remain confidential and would not have any bearing on their standing in the programme. Participants ranged from first year medical students to residents in their final year. The majority of the participants were female $(\mathrm{n}=97,53.6 \%)$, between the ages of 22 and $45(\mathrm{M}=28.7$, $\mathrm{SD}=4.01$ ), and working in a variety of residency specialisations, with the top three being internal medicine, emergency medicine, and general surgery. We also obtained 167 supervisor reports (ie, chief/senior residents, programme directors, attending physicians) on 132 trainees to compare to self-reports of leadership. Medical trainees did not have access to the results of the supervisor reports and the supervisors did not have access to the trainees' self-reports, maintaining the confidentiality of responses for all participants.

\section{Measuring leadership}

Self-report leadership surveys were composed of previously well-validated scales and subscales to assess both the traits and behaviours that define each competency domain, measured on a five-point Likert scale from 1 (never/strongly disagree) to 5 (always/strongly agree) (see table 2 for measures). This is in recognition that the trait and behavioural perspective are both central to understanding leadership. Further, we explored the validity of single-item Visual Analogue Scales (VASs) to address each of the competency domains for use in rapid-assessment scenarios (eg, following patient encounters) or for rating multiple individuals. Therefore, we included numerical rating scales to ask how frequently participants exhibited each competency domain definition from 0 (never) to 100 (all of the time). Medical trainees completed the trait and behaviour measures as well as the VASs, while supervisors completed only the VASs in reference to leadership qualities of the trainees.

\section{Clinical performance}

To evaluate leadership relative to existing clinical performance assessments, we retrieved up to three $e^{c}$ performance evaluations per trainee (399 total evaluations for 157 participants) that were completed at approximately the same time as the leadership self-report (November 2017-September 2018). These are clinical evaluations that are done regularly as part of the medical trainees' on-going educational assessment and were not uniquely collected for this study. Reports were collated in the spring and summer of 2019. Clinical evaluation measures generally ranged from 12 to 34 items, were rated on a Likert scale (eg, 1 (poor) 
to 5 (excellent)) and covered topics such as medical expertise, professionalism, advocacy and overall performance. To account for interdepartmental differences in clinical appraisal measures, final performance scores were $\mathrm{z}$-score standardised to facilitate analysis across participants and settings.

\section{Analysis}

We note that the primary method of data analysis included Pearson correlations, as computed in SPSS V.26.0 for Mac (IBM Corp).

\section{RESULTS}

Self and supervisor perceptions of leadership

Overall, results suggest that the single-item VASs are a useful approach to appraise leadership via trainee evaluation by supervisors and self (table 3), with self-ratings in particular being associated with relevant traits and behaviours, but with disconnect between self and supervisors on the VAS. The selfreport VAS ratings for the seven competency domains typically demonstrated small $(\mathrm{r}<0.20)$ to moderate $(\mathrm{r}=0.20-0.30)$ intercorrelations. ${ }^{24}$ This indicates that each competency domain is likely tapping into unique features of leadership. Similar trends are reflected in the supervisor's VAS ratings of trainees' leadership abilities, with most of the relationships among the competency domains being classified as moderate or above $(r>0.30){ }^{24}$ Higher correlations among the competency domains in supervisor reports may reflect a halo effect ${ }^{25}$ where trainees that are perceived as good leaders in one area are more likely to be seen as good leaders overall.

However, we found that VAS self-reports of leadership did not typically tend to correlate highly with corresponding supervisor VAS evaluations of leadership ( $\mathrm{r}$ range from -0.22 to 0.332 ; table 3). This demonstrates a potential disconnect between trainees' self-perceptions and perceptions of their supervisors. In some cases, trainees and supervisors tended to agree, such as the convergence between self and supervisor ratings of Civility. However, in other cases, those that perceived themselves as possessing a valuable leadership competency domain actually received more negative evaluations from their supervisor. An example of this is in Ethical and Social Responsibility, where trainees who rated themselves highly were actually perceived as worse leaders overall by their supervisors $(r=-0.175$, $\mathrm{p}=0.045$ ). Overall, while the VASs are useful tools for rapidly assessing leadership, trainees and supervisors may have different perceptions or understanding of whether that trainee embodies that competency domain and different exposure to enacted leadership behaviours by trainees.

\section{Traits and behaviours associated with self-rated leadership}

Evidence for the traits and behaviours that underlie the leadership competency domains can be found in table 4. Specifically, these correlations demonstrate the extent to which the self-rated VAS measures for each competency (and the mean of the VAS measures) are associated with more nuanced trait and behavioural measures. In line with leadership theories, trainees with certain traits and behavioural tendencies are more likely to perceive themselves as performing well in certain leadership competency domains, although there are a few exceptions. Some traits and behaviours seem to contribute to multiple leadership competency domains, indicating that several traits and behaviours are likely to lead to high self-rated leadership perceptions in multiple domains (eg, honesty). Overall, results indicated that many of the expected traits and behaviours were associated with relevant VAS scores.

\section{Traits and behaviours associated with supervisor-rated leadership}

Next, we examined supervisor VAS ratings of leadership in relation to trainees' self-reported traits and leadership behaviours ${ }^{\mathrm{d}}$. Overall, results indicated that many of the relationships between self-reported traits and behaviours and supervisor VAS ratings are either null or in the opposite direction than expected (ie, negative rather than positive correlations; see table 5). For example, while trainees that rate themselves high in particular traits and behaviours also perceive themselves as good leaders in that competency domain, in many cases, higher levels of these traits and behaviours were not associated with supervisor perceptions of leadership competency domains, or were negatively associated with supervisor perceptions of leadership. One example of this is the negative correlations of self-ratings of transformational leadership with several supervisory ratings of leadership in the $-0.20 \mathrm{~s}$. Further, numerous relationships were weaker than expected, indicating that supervisors may not recognise leadership potential and behaviours.

In addition, results indicated that trainees may not be perceived negatively across the board when engaging in problematic behaviours. For example, trainees that engage in less civil behaviours (eg, putting down peers, ridiculing others) are perceived as less civil by their leaders $(r=0.28, p<0.05)$, but are not perceived as poor leaders overall. Rather, trainees with higher civility behaviour scores are actually less likely to be perceived as a leader in two of the seven competency domains ( $\mathrm{rs}=-0.15$, and $-0.22, n s)$, and had no relation to leadership $(r<0.08)$ in four out of the seven. We observe a similar trend for ethical leadership, wherein those who had higher self-reported ethical leadership scores did not garner higher corresponding ethics and social responsibility ratings from supervisors $(r=0.03$, $n s)$, and indeed, ethical leadership was not significantly associated (with correlations typically in the negative direction) with all other supervisor-rated leadership criteria ( $r$ s range from -0.00 to -0.21 ).

Conversely, those that are perceived as good leaders by supervisors are particularly more likely to be high on the extraversion facet of social boldness, which significantly correlated with five of the seven supervisor-rated leadership competencies, and overall supervisor-rated leadership $(r=0.30, \mathrm{p}<0.05)$. Indeed, social boldness appeared to be the primary driver of supervisorrated leadership. Similarly, although non-significant, individuals high in the two facets of agreeableness appeared to be rated more highly overall $(r s=0.15$ and $0.23, n s)$.

\section{Leadership and clinical performance}

Table 6 demonstrates the relationship between self-reported and supervisor-reported leadership competency domains (using the VAS) and clinical performance. While self-reports of leadership competency domains are largely unrelated to how trainees clinically perform, the relationship between supervisor reports and clinical performance highlight how leadership is viewed by supervisors. Supervisor ratings of all seven leadership competency domains are moderately related to ratings of clinical performance, demonstrating that trainees who are perceived as good leaders are also viewed as strong clinical performers. These relationships are moderate enough to suggest that leadership and performance ratings are distinct. This is contrasted by the null and sometimes negative relationships between self-rated 


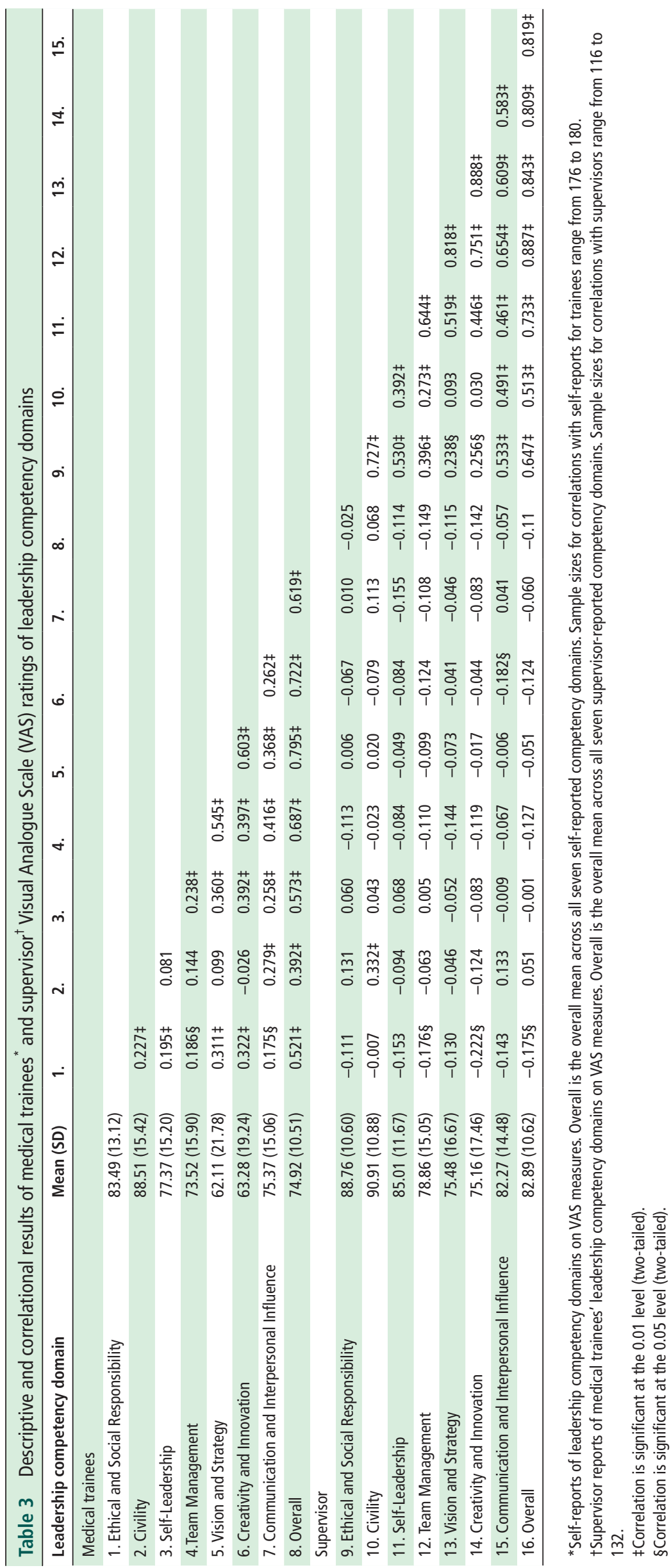


Table 4 Descriptive and correlational results of medical trainees* self-reported leadership competency domains on the Visual Analogue Scale (VAS) with self-reported trait and behavioural measures

\begin{tabular}{|c|c|c|c|c|c|c|c|c|c|}
\hline & Mean (SD)† & 1. & 2. & 3. & 4. & 5. & 6. & 7. & Overallף \\
\hline \multicolumn{10}{|c|}{ 1. Ethical and Social responsibility } \\
\hline Honesty-humility & $3.76(0.64)$ & $0.311 \ddagger$ & $0.268 \S$ & $0.237 \S$ & 0.024 & $0.256 \S$ & $0.235 \S$ & 0.056 & $0.295 \ddagger$ \\
\hline Sincerity & $3.34(0.84)$ & $0.320 \ddagger$ & $0.216 \S$ & $0.215 \S$ & 0.033 & $0.215 \S$ & $0.251 \S$ & 0.035 & $0.275 \S$ \\
\hline Fairness & $4.18(0.70)$ & 0.179 & $.223 \S$ & 0.171 & -0.006 & 0.203 & 0.125 & 0.047 & 0.200 \\
\hline Ethical leadership & $3.56(0.46)$ & $0.352 \ddagger$ & 0.154 & 0.044 & 0.150 & 0.170 & 0.136 & 0.131 & $0.249 \S$ \\
\hline \multicolumn{10}{|l|}{ 2. Civility } \\
\hline Agreeableness & $3.34(0.60)$ & -0.051 & $0.241 \S$ & 0.003 & -0.203 & 0.041 & 0.102 & 0.152 & 0.069 \\
\hline Forgiveness & $3.03(0.80)$ & -0.003 & 0.195 & -0.003 & -0.125 & 0.080 & 0.075 & 0.180 & 0.098 \\
\hline Patience & $3.66(0.64)$ & -0.092 & 0.206 & 0.003 & $-0.223 \S$ & -0.023 & 0.096 & 0.058 & 0.007 \\
\hline Civility behaviours & $4.65(0.37)$ & 0.087 & 0.178 & 0.127 & 0.029 & 0.186 & 0.095 & 0.221 & 0.214 \\
\hline \multicolumn{10}{|l|}{ 3. Self-Leadership } \\
\hline Conscientiousness & $3.81(0.58)$ & 0.124 & 0.167 & $0.419 \ddagger$ & 0.025 & $0.363 \ddagger$ & $0.217 \S$ & 0.053 & $0.312 \ddagger$ \\
\hline Diligence & $4.09(0.54)$ & $0.253 \S$ & 0.141 & $0.460 \ddagger$ & 0.114 & $0.510 \ddagger$ & $0.398 \ddagger$ & 0.019 & $0.437 \ddagger$ \\
\hline Organisation & $3.54(0.80)$ & 0.008 & 0.146 & $0.297 \ddagger$ & -0.043 & 0.181 & 0.047 & 0.063 & 0.156 \\
\hline Learning goal orientation & $4.42(0.43)$ & $0.238 \S$ & 0.083 & $0.318 \ddagger$ & -0.011 & $0.362 \ddagger$ & $0.351 \ddagger$ & -0.119 & 0.294 \\
\hline \multicolumn{10}{|l|}{ 4. Team Management } \\
\hline Initiating leadership & $3.75(0.57)$ & 0.132 & 0.164 & 0.026 & $0.272 \S$ & $0.218 \S$ & $0.223 \S$ & 0.177 & $0.299 \ddagger$ \\
\hline Consideration leadership & $4.12(0.38)$ & $0.355 \ddagger$ & $0.282 \S$ & $0.363 \ddagger$ & 0.202 & $0.274 \S$ & $0.263 \S$ & 0.212 & $0.444 \ddagger$ \\
\hline \multicolumn{10}{|l|}{ 5. Vision and Strategy } \\
\hline Strategic leadership & $3.59(0.49)$ & 0.153 & 0.121 & $0.278 \ddagger$ & $0.256 \S$ & $0.364 \ddagger$ & $0.434 \ddagger$ & $0.270 \S$ & $0.443 \ddagger$ \\
\hline Transformational leadership & $3.58(0.51)$ & 0.212 & 0.065 & $0.259 \S$ & $0.344 \ddagger$ & $0.450 \ddagger$ & $0.301 \ddagger$ & $0.453 \ddagger$ & $0.492 \ddagger$ \\
\hline \multicolumn{10}{|l|}{ 6. Innovation and Creativity } \\
\hline Openness to experience & $3.41(0.62)$ & 0.067 & -0.146 & -0.007 & -0.190 & 0.011 & 0.153 & 0.021 & -0.003 \\
\hline Creativity & $3.38(0.77)$ & 0.157 & -0.046 & 0.142 & -0.117 & 0.035 & $0.220 \S$ & 0.043 & 0.106 \\
\hline Unconventionality & $3.44(0.64)$ & -0.061 & $-0.231 \S$ & -0.185 & $-0.229 \S$ & -0.022 & 0.031 & -0.012 & -0.136 \\
\hline Propensity to innovate & $3.68(0.46)$ & 0.123 & -0.091 & 0.200 & $0.313 \ddagger$ & $0.441 \neq$ & $0.534 \ddagger$ & 0.159 & $0.417 \ddagger$ \\
\hline \multicolumn{10}{|c|}{ 7. Communication and Interpersonal Influence } \\
\hline Extraversion & $3.44(0.54)$ & 0.078 & -0.021 & $0.218 \S$ & 0.132 & 0.109 & 0.142 & $0.280 \S$ & 0.215 \\
\hline Social boldness & $3.20(0.61)$ & 0.014 & -0.083 & 0.163 & 0.100 & 0.034 & 0.145 & $0.303 \ddagger$ & 0.156 \\
\hline Sociability & $3.70(0.61)$ & 0.125 & 0.041 & $0.224 \S$ & 0.135 & 0.161 & 0.107 & 0.186 & $0.224 \S$ \\
\hline Political skill & $4.18(0.47)$ & $0.222 \S$ & 0.099 & $0.353 \ddagger$ & 0.201 & $0.257 \S$ & $0.258 \S$ & $0.240 \S$ & $0.361 \ddagger$ \\
\hline Clinical communication & $4.14(0.37)$ & 0.119 & 0.226 & -0.007 & 0.047 & 0.007 & 0.049 & 0.010 & 0.082 \\
\hline
\end{tabular}

Columns represent self-report VAS scores, while rows indicate trait and behaviour scores self-rated by medical trainees. Bolded values highlight correlations that would indicate convergence between VAS and self-report trait and behaviour measures.

*Sample sizes for correlations range from 67 to 180.

tMeasured on a 1 (never/strongly disagree) to 5 (always/strongly agree) Likert scale.

¥Correlation is significant at the 0.01 level (two-tailed).

$\S$ Correlation is significant at the 0.05 level (two-tailed).

ПOverall represents the overall mean of VSA self-ratings on all seven leadership competency domains.

leadership and clinical performance. Collectively, trainees that rate themselves as high performers in the leadership competency domains are either rated as being lower clinical performers (in the case of Ethical and Social Responsibility), or are not associated with clinical performance, demonstrating that trainees who believe they are effectively engaging in leadership practices are not necessarily viewed as better performers by their supervisors, or in some cases are being perceived negatively by their supervisors.

The self-reported trait and behavioural measures of leadership also demonstrate interesting relationships with performance. Those that rate themselves high on ethical leadership $(r=-0.203$, $\mathrm{p}=0.07)$, strategic leadership $(\mathrm{r}=-0.230, \mathrm{p}=0.048)$, and transformational leadership $(\mathrm{r}=-0.269, \mathrm{p}=0.03)$ are generally perceived to have lower mean performance. However, those that are high in overall conscientiousness $(r=0.114-0.149$, n.s.), organisation $(\mathrm{r}=0.109-0.132$, n.s. $)$, and social boldness $(\mathrm{r}=0.150-0.189$, n.s. $)$, demonstrate small but relatively stable positive relationships with mean clinical performance. We should note that although some of these are not statistically significant (likely due to low sample sizes for this component of the analysis) the effect sizes are in the typical range for small to medium effect sizes in individual differences research. ${ }^{26}$ There are also a few consistently null relationships that are particularly relevant. Traits such as fairness $(\mathrm{r}=-0.002$ to 0.008 , n.s.), honesty $(\mathrm{r}=-0.027$ to 0.038, n.s. $)$, patience $(\mathrm{r}=-0.059$ to 0.009 , n.s. $)$, and sincerity ( $\mathrm{r}=-0.044$ to 0.081, n.s.) do not predict clinical performance despite these being essential underlying factors to good clinical leadership. Scores of civility $(r=-0.042$ to 0.002 , n.s.) were also largely unrelated to clinical performance across measurements. While this illustrates that perceptions of engaging with colleagues in a civil manner does not translate to good performance, it also means that trainees that do engage in uncivil behaviours (eg, bullying) are not punished on their performance scores. In sum, preliminary evidence suggests that trainees' 
Table 5 Descriptive and correlational results of medical trainees ${ }^{*}$ self-rated traits and behaviours with leadership Visual Analogue Scales (VASs) as rated by supervisors

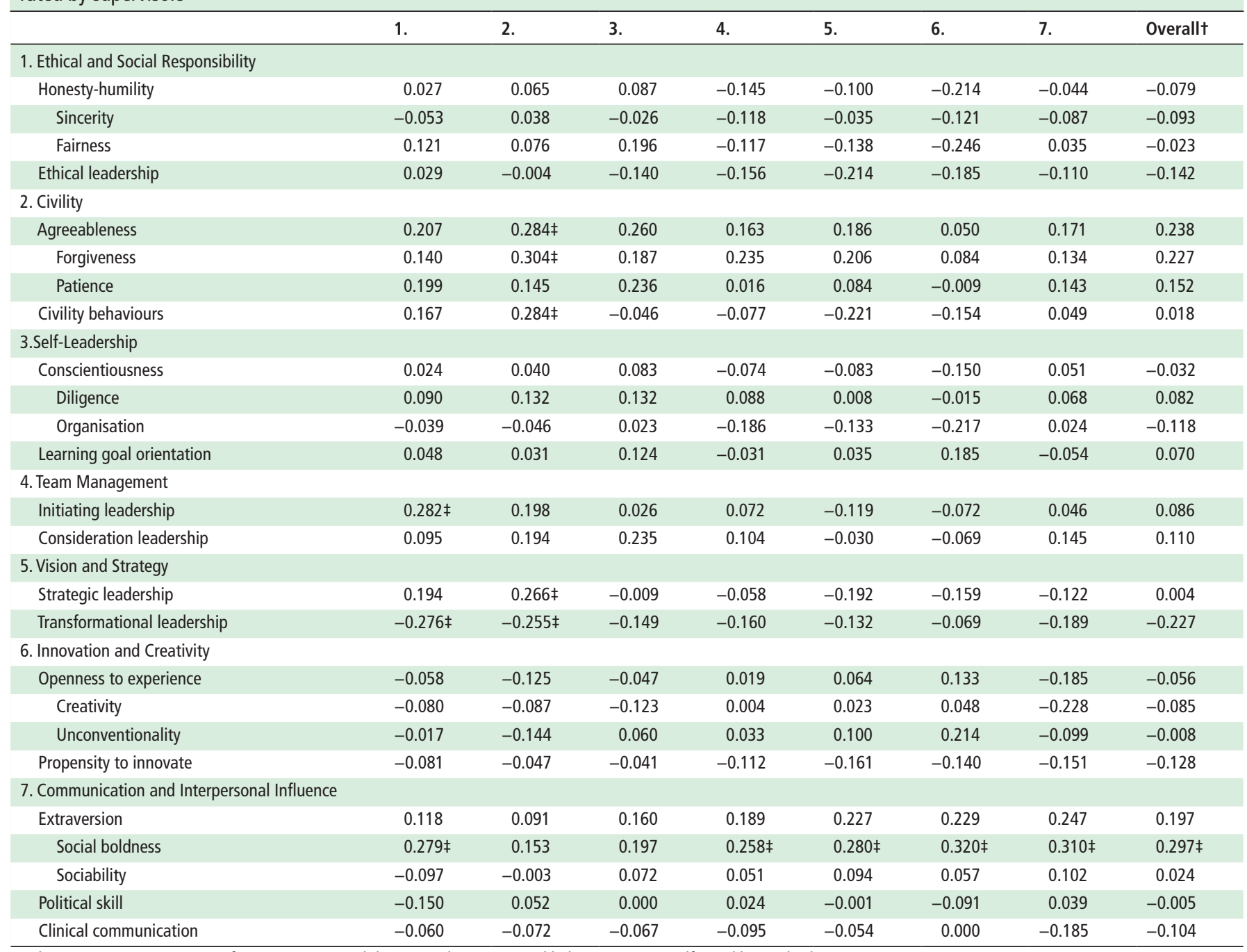

Columns represent VAS scores from supervisors, while rows indicate trait and behaviour scores self-rated by medical trainees.

*Sample sizes for correlations range from 45 to 70 .

tOverall represents the overall mean of VSA supervisor ratings of trainees on all seven leadership competency domains.

‡Correlation is significant at the 0.05 level (two-tailed).

honesty, patience, fairness, sincerity and civility towards others do not seem to play a role in clinical performance evaluations.

\section{DISCUSSION}

Our study developed and explored a framework of seven leadership competency domains deemed essential to good medical leadership through interviews and surveys with programme stakeholders. Medical trainees reported on their own leadership traits and behaviours, while their supervisors reported on the extent the trainees embodied each of the competency domains, resulting in insightful multi-source data. We also examined how perceptions of leadership were related to clinical performance to understand the relationship between leadership competency domains, traits, and behaviours, and clinical performance ratings. This study addresses the need for competency-based leadership approaches in medical education and goes further than previous studies by examining ways to measure these competencies, utilising existing validated trait, behavioural, and leadership style measures, and examining their relationship to existing measures of clinical performance.
The findings suggest that VAS scales can be an effective way to rapidly assess leadership, while long-scale formats that assess traits and behaviours can be used to identify potential leaders and evaluate current leadership behaviours. We found that perceptions of leadership differed between trainees and supervisors, potentially indicating that trainees and supervisors have different implicit schemas about how to behave as (and whether one is) an ideal medical leader despite similar features of leadership identified in Phase One.

We also found that traits and behaviours traditionally associated with leadership, and identified by SMEs in the medical context, were not always perceived favourably by supervisors, resulting in lower leadership and performance scores. For example, transformational leadership is traditionally viewed as an optimal form of leadership ${ }^{27}$; however in this context, self-ratings of transformational leadership were associated in some cases with poorer leadership and clinical performance evaluations. These results require deeper exploration and are an important area for further research. Perhaps acute care clinicians who are trained to make clinical decisions on shorter term frames are not as attuned to 
Table 6 Correlational results of medical trainees* and supervisort Visual Analogue Scale (VAS) ratings of leadership competency domains with clinical performance measures across specialties

\begin{tabular}{|c|c|c|c|}
\hline Leadership competency & Performance 1 & Performance 2 & Mean performance \\
\hline Ethical and Social Responsibility & $-0.203 \S$ & -0.079 & -0.115 \\
\hline Self-Leadership & 0.132 & -0.029 & -0.001 \\
\hline Team Management & 0.018 & 0.040 & -0.002 \\
\hline Vision and Strategy & -0.008 & 0.003 & -0.025 \\
\hline Communication and Interpersonal Influence & -0.122 & -0.080 & -0.123 \\
\hline Overall & -0.062 & -0.040 & -0.083 \\
\hline \multicolumn{4}{|l|}{ Supervisor VAS ratings } \\
\hline Ethical and Social Responsibility & 0.161 & 0.2579 & $0.233 \S$ \\
\hline Civility & 0.134 & 0.2689 & $0.225 \S$ \\
\hline Self-Leadership & 0.136 & 0.3719 & 0.3019 \\
\hline Communication and Interpersonal Influence & $0.258 \S$ & $0.286 \uparrow$ & 0.309 - \\
\hline Overall & $0.243 \S$ & 0.3539 & $0.361 \rrbracket$ \\
\hline
\end{tabular}

*Sample sizes for VAS self-reports for trainees range from 94 to 157. Overall is the overall mean across all seven self-reported competency domains.

tSample sizes for VAS supervisor reports range from 68 to 118. Overall is the overall mean across all seven supervisor-reported competency domains. ¥Mean across two measurement points.

$\S$ Correlation is significant at the 0.05 level (two-tailed).

ПCorrelation is significant at the 0.01 level (two-tailed).

longer term cycles required to assess ethics, strategy, and system transformation. As a result, features that make for strong patient interactions and interpersonal clinical team interactions, and are highly observable (such as extraversion) are privileged as leadership traits because they are visible and relatable to oneon-one clinical care. It is also possible professionalised clinicians, who are largely untrained in leadership and disconnected from system administrative work, adopt popular perceptions of leadership as standard-bearers of quality leadership, favouring traits like agreeableness and extraversion. On the other hand, perhaps transformational medical trainee leaders devote finite resources to preferentially develop their leadership skills over their clinical development. This finding is important to clarify because the perception of leaders and leadership informs who is encouraged and recruited into leadership roles, how successful leaders are at marshalling change, and how they are judged for all the behaviours that move their organisation and members towards ethical, strategic system transformation.

Additionally, Civility and Vision were ranked highly in Phase One by the SMEs but unassociated (or negatively associated) with supervisor perceptions in some cases. This was also true for the relationships between multi-faceted competency domains overall; trainees who perceived themselves as good leaders were sometimes seen as poor leaders and clinical performers by their supervisors, or their perceptions did not match their supervisors.

While some of the identified traits and behaviours align with the typology of an ideal medical leader, in practice, many of them seem to go unrecognised or are incorrectly perceived as indicators of poor leadership ability. This highlights incongruence between key areas of leadership development and the outcomes of current medical education. Some behaviours, such as self-rated incivility, were unrelated to performance, indicating that trainees that engage in negative behaviours are not necessarily seen as poorer clinicians or leaders, despite the high prevalence of harassment faced by trainees, ${ }^{28}$ and its associations with adverse patient care and physician burnout. ${ }^{29}$ Rather, the traits that appear to positively influence clinical performance perceptions are around organisation, conscientiousness and being socially bold, although the sample sizes with traits and behaviours were somewhat smaller in some cases, and so should be treated cautiously.

Current organisational culture and reward systems may perpetuate misalignment between desired and enacted forms of leadership. Especially because this mismatch might reinforce discrimination in the workplace such as gender inequity, ${ }^{30}$ it is important to foster multicompetency leadership. Leadership capabilities are essential tools for medical professionals as they progress through their careers and they may find themselves ill-equipped to be effective leaders in clinical and administrative roles if they were punished (or not rewarded) for engaging in positive leadership behaviours during their training. Failure to consider leadership ability as a critical component of clinical education is a failure to prepare trainees to effectively lead complex institutions. Such failure could propagate structural forms of discrimination that lead to workplace inequities and inequitable patient outcomes.

From our findings, we make three recommendations for improving leadership in medical education:

1. Use validated, theory-driven competency frameworks when building leadership curriculum and evaluating leadership behaviours. Given the multidisciplinary and interconnected nature of healthcare teams in the modern medical profession, we recommend medical educators use a standardised frame of leadership. A multicompetency view aligns with broader theoretical perspectives on leadership and provides a framework to develop leadership curriculum. Although our final framework, derived in 2015, did not include Diversity and Intercultural awareness, we believe this model should be expanded to include this important competency domain in future studies. Although some of the competency domains 
we do include, such as Ethics and Social Responsibility and Civility, indirectly support Diversity, we believe Diversity and Intercultural Awareness is an independently important competency.

2. Align reward systems with demonstrated leadership competencies using both the short- and long-term assessments. Assess trainees' leadership behaviours on an on-going basis in line with recent emphasis on competency based medical education. ${ }^{31}$ We recommend programme directors implement annual (eg, full evaluation of all competency domains) in addition to event based (eg, VASs) evaluations to capture long term outcomes of leadership that are not easily assessed in the short term(eg, vision).

3. Train to identify and encourage effective leadership at all levels of the organisation.

Teach assessors and trainees how to evaluate leaders: To accurately evaluate leadership, raters (ie, self, peer, trainees, supervisors) should understand how to recognise leadership behaviours. We recommend frame-of-reference training, ${ }^{32}$ a technique used to help evaluators improve the accuracy of their performance ratings through exercises that build and alter schemas to more accurateley define effective leadership. Using validated measures of leadership that focus on observable behaviours may also improve accuracy of leadership assessments.

Assess leadership early: Leadership training and assessment training should not be reserved for those in formal leadership positions but should include medical educators and trainees. This approach shifts the focus from training individuals to be good leaders after they are in leadership positions, to developing a broad base of diverse organisational talent with the skills and qualities to excel in leadership positions.

Despite the multisource strengths of our study, it is not without limitations. Although the use of validated measures increases the reliability of our findings, incomplete and missing data creates variability in our sample sizes, potentially affecting the stability of our relationships, particularly in regards to trait and behavioural measures. As a result, we largely comment on effect sizes rather than statistical significance. Additionally, our sample was limited to a single institution, potentially limiting generalisability to other medical education programmes. Further, participants self-selected into our study and were offered an incentive. Although these practices are consistent with research in this area and the time commitment required of participants, some trainees may have been more inclined to participate than others. However, our sample covered trainees with a broad range of clinical experience and specialisations across numerous hospital sites, reflecting the general population of medical trainees. Our competency framework is grounded in the leadership literature and refined through consultation with SMEs, hopefully reducing idiosyncrasies. Future studies should expand the sample size and diversity across institutions to further validate our framework and measurement approach. Future validation efforts should also include comparisons between healthcare specialties (eg, public health, primary care, acute care) to examine if the negative relationship between leadership behaviours and perceptions of clinical performance persist beyond acute care. We also recommend the development and validation of longer-term leadership intervention programmes (eg, frame-of-reference training, ${ }^{31}$ case studies) and assessment programmes built around the seven competency domains, such as civility, given its relevance to issues in medicine.
Twitter Samantha K. Jones @samanthakjones and Aleem Bharwani @ AleemBharwani

Acknowledgements The authors wish to thank Dr. Babatunde Ogunfowora for his early assistance on the development of the leadership competencies. The authors would also like to thank the faculty, staff, and leadership at the Cumming School of Medicine for their assistance and support over the course of this project. Laslty, we would also like to thank the Canadian Centre for Advanced Leadership for their support of this research.

Contributors $A B$ and $J B$ were involved in project conception and in Phase One analysis and Phase Two competency development. KHC and SKJ refined the competency measurement protocol and collected the data with support from $A B$ and JB. SKJ conducted the data analysis with support from JB. The manuscript was written by SKJ with contributions from all authors. All authors have read and approved this manuscript.

Funding This research was supported by the Indigenous, Local, and Global Health Office and the Canadian Centre for Advanced Leadership Research in Business Grant (2018-2019).

Competing interests None declared.

Patient consent for publication Not required.

Ethics approval The Conjoint Health Research Ethics Board approved this research on August 18, 2017 (REB17-0591). This project gained ethics approval from the institutional ethics board.

Provenance and peer review Not commissioned; externally peer reviewed.

Data availability statement Data are available from the first author upon reasonable request. All data relevant to the study are included in the article and a full correlation table of the study variables is available as a supplementary material.

Author note $\cdot{ }^{\mathrm{a}}$ We also had peers complete this measure, and received peer ratings for 79 trainees. We chose to focus on the supervisor reports, given their influential role in identifying and training leadership. Peer results are available from the first author on request; ${ }^{b}$ Samples sizes for each correlation reported in the results section range from 45 (for some scale measures) to 180 due to missing data. Exact ranges are reported in the notes of each table and a full correlation table with sample sizes associated with all possible correlations are available as a online supplemental material; · ' Given the small sample size for the third measurement point, we focus on the first two performance measures; ${ }^{d}$ As sample sizes were lower for traits and behaviours, we discuss both statistically significant findings, and mention trends that reflect effect sizes typically meaningful in individual difference research ${ }^{26}$ (ie, above 0.10)

Supplemental material This content has been supplied by the author(s). It has not been vetted by BMJ Publishing Group Limited (BMJ) and may not have been peer-reviewed. Any opinions or recommendations discussed are solely those of the author(s) and are not endorsed by BMJ. BMJ disclaims all liability and responsibility arising from any reliance placed on the content. Where the content includes any translated material, BMJ does not warrant the accuracy and reliability of the translations (including but not limited to local regulations, clinical guidelines, terminology, drug names and drug dosages), and is not responsible for any error and/or omissions arising from translation and adaptation or otherwise.

Open access This is an open access article distributed in accordance with the Creative Commons Attribution Non Commercial (CC BY-NC 4.0) license, which permits others to distribute, remix, adapt, build upon this work non-commercially, and license their derivative works on different terms, provided the original work is properly cited, appropriate credit is given, any changes made indicated, and the use is non-commercial. See: http://creativecommons.org/licenses/by-nc/4.0/.

\section{ORCID iDs}

Samantha K. Jones http://orcid.org/0000-0002-5881-8740

Aleem Bharwani http://orcid.org/0000-0002-5981-3589

\section{REFERENCES}

1 Wong CA, Cummings GG. The relationship between nursing leadership and patient outcomes: a systematic review. J Nurs Manag 2007;15:508-21.

2 Gilbert S, Kelloway E. Development and validation of the leads scale. Can J Nurs Leadersh 2018;31:32-41.

3 van der Wal MA, Schönrock-Adema J, Scheele F, et al. Supervisor leadership in relation to resident job satisfaction. BMC Med Educ 2016;16:1-7.

4 Varkey P, Peloquin J, Reed D, et al. Leadership curriculum in undergraduate medical education: a study of student and faculty perspectives. Med Teach 2009;31:244-50

5 Blumenthal DM, Bernard K, Bohnen J, et al. Addressing the leadership gap in medicine: residents' need for systematic leadership development training. Acad Med 2012;87:513-22 
6 Warren OJ, Carnall R. Medical leadership: why it's important, what is required, and how we develop it. Postgrad Med J 2011;87:27-32.

7 Steinert Y, Naismith L, Mann K. Faculty development initiatives designed to promote leadership in medical education. A BEME systematic review: BEME guide No. 19. Med Teach 2012;34:483-503.

8 Webb AMB, Tsipis NE, McClellan TR, et al. A first step toward understanding best practices in leadership training in undergraduate medical education: a systematic review. Acad Med 2014;89:1563-70.

9 Çitaku F, Violato C, Beran T, et al. Leadership competencies for medical education and healthcare professions: population-based study. BMJ Open 2012;2:e000812.

10 Clark J, Armit K. Leadership competency for doctors: a framework. Leadersh Health Serv 2010;23:115-29.

11 Chen T-Y. Medical leadership: an important and required competency for medical students. Ci Ji Yi Xue Za Zhi 2018;30:66-70.

12 Frank JR, Snell L, Sherbino J, eds. CanMEDS 2015 Physician Competency Framework. Ottawa: Royal College of Physicians and Surgeons of Canada, 2015.

13 NHS Leadership Academy. The healthcare leadership model. version 1.0. Leeds: NHS Leadership Academy, 2013.

14 Xirasagar S. Transformational, transactional among physician and laissez-faire leadership among physician executives. J Health Organ Manag 2008;22:599-613.

15 Howieson B, Thiagarajah T. What is clinical leadership? A journal-based meta-review. Int J Clin Leadersh 2011:17:7-18.

16 Edmonstone J. Clinical leadership: the elephant in the room. Int J Health Plann Manage 2009;24:290-305.

17 Day DV, Antonakis J. Leadership: Past, Present and Future. In: Day DV, Antonakis J, eds The nature of leadership. Thousand Oaks, CA: Sage Publications, 2012: 3-25.

18 Day DV, Fleenor JW, Atwater LE, et al. Advances in leader and leadership development: a review of 25years of research and theory. Leadersh Q 2014;25:63-82.

19 Bharwani A, Kline T, Patterson M, et al. Barriers and enablers to academic health leadership. Leadersh Health Serv 2017;30:16-28.

20 Bharwani A, Kline T, Patterson M. A stakeholder-based approach to leadership development training: the case of medical education in Canada. Int J Train Dev 2017:21:211-23.

21 Bharwani A, Kline T, Patterson M. Perceptions of effective leadership in a medica school context. Can Med Educ J 2019:10:e101-6.

22 Brown ME, Treviño LK, Harrison DA. Ethical leadership: a social learning perspective for construct development and testing. Organ Behav Hum Decis Process 2005;97:117-34.

23 Stogdill RM. Leadership, membership and organization. Psychol Bull 1950:47:1-14.

24 Hemphill JF. Interpreting the magnitudes of correlation coefficients. Am Psychol 2003:58:78-80.
25 Nisbett RE, Wilson TD. The halo effect: evidence for unconscious alteration of judgments. J Pers Soc Psychol 1977;35:250-6.

26 Gignac GE, Szodorai ET. Effect size guidelines for individual differences researchers. Pers Individ Dif 2016;102:74-8.

27 Judge TA, Piccolo RF. Transformational and transactional leadership: a meta-analytic test of their relative validity. J App/ Psycho/ 2004;89:755-68.

28 Leisy HB, Ahmad M. Altering workplace attitudes for resident education (A.W.A.R.E.): discovering solutions for medical resident bullying through literature review. $B M C$ Med Educ 2016;16:1-10.

29 Pattani R, Ginsburg S, Mascarenhas Johnson A, et al. Organizational factors contributing to incivility at an academic medical center and systems-based solutions: a qualitative study. Acad Med 2018;93:1569-75.

30 Ruzycki SM, Freeman G, Bharwani A, et al. Association of physician characteristics with perceptions and experiences of gender equity in an academic internal medicine department. JAMA Netw Open 2019:2:e1915165.

31 Frank JR, Snell LS, Cate OT, et al. Competency-based medical education: theory to practice. Med Teach 2010:32:638-45.

32 Gorman CA, Rentsch JR. Evaluating frame-of-reference rater training effectiveness using performance schema accuracy. J Appl Psychol 2009;94:1336-44.

33 Lee K, Ashton MC. Psychometric properties of the HEXAC0-100. Assessment 2018:25:543-56.

34 Tepper BJ. Consequences of abusive supervision. Acad Manag J 2000;43:178-90.

35 Button SB, Mathieu JE, Zajac DM. Goal orientation in organizational research: a conceptual and empirical Foundation. Organ Behav Hum Decis Process 1996:67:26-48.

36 Stogdill RM. Manual for the leader behavior description Questionnaire-Form XII: an experimental revision. Bureau of business research, College of Commerce and administration. Columbus, OH: Ohio State University, 1963.

37 Schoemaker PJH, Krupp S, Howland S. Strategic leadership: the essential skills. Harv Bus Rev 2013;91:1-5.

38 Bass BM, Avolio BJ. Transformational leadership development: manual for the multifactor leadership questionnaire. Palo Alto, CA: Consulting Psychologist Press, 2004

39 Burningham C, West MA. Individual, climate, and group interaction processes as predictors of work team innovation. Small Group Res 1995;26:106-17.

40 Ahearn KK, Ferris GR, Hochwarter WA, et al. Leader political skill and team performance. J Manage 2004;30:309-27.

41 Makoul G. The SEGUE framework for teaching and assessing communication skills. Patient Educ Couns 2001;45:23-34. 